\title{
Tumour necrosis factor-alpha level among travellers contracted with dengue virus in Bali
}

\author{
$N W$ Widhidewi*, $S$ Masyeni, and $H$ Sukmawati \\ Universitas Warmadewa Denpasar, Faculty of Medical and Health Sciences, Indonesia
}

\begin{abstract}
Dengue infection burden has been predicted increase three times greater recently. Severe dengue infection associated with the high generation of inflammatory cytokines leads to vascular endothelial instability. Hence, the current study aim to evaluate the level of TNF- $\alpha$ among travellers infected with DENV in Bali. An observational prospective study has been conducted on travellers presenting with dengue symptoms who admitted at Kasih Ibu Hospital Bali in 2017. Majority of the sample was female (61\%) which median (range) age was 29 (15.4-73.1) years old. The median (range) nadir platelet was 74(29-194) 103 cell $/ \mu \mathrm{L}$. The temporal predominant serotype was DENV-3 (29.3\%), followed by DENV-2 (24.4\%), DENV-1 (13.6\%), and DENV-4 (2.4\%). The study found concurrent DENV infection. Diagnosis of DF was almost equal with DHF. Level of TNF- $\alpha$ found 3 times higher in DHF than DF patients.
\end{abstract}

\section{Introduction}

Dengue virus (DENV) infection has become a major threat and serious public health problem worldwide. More than 2.5 billion people in tropical and sub-tropical countries are at high risk to get DENV infection [1].

The prevalence of DENV infection has been reported to be increase 3 times greater than the WHO prediction, recently [2]. The annual DENV case has been reported as high as 390 million cases per year with 96 million symptomatic cases [3]. Mortality rate of DENV may exceed $5 \%$ in particular population such as too young cases, elderly, pregnant, immune compromise or people with pre-existing illnesses [3].

Dengue virus is a RNA virus belong to genus Flavivirus, consist of 4 antigenically distinct serotype, DENV-1 through DENV-4 [4]. Infection by one DENV serotype confers life-long immunity, and partial nonneutralizing antibody to the others serotype [5], [6]. The genome of the DENV encode 3 structural proteins and 7 non-structural proteins which involved in virus replication or DENV pathogenesis. Role of nonstructural protein (NS)-1 in dengue severity has been evaluated elsewhere [7], [9].

Clinical manifestation of DENV vary mostly mild asymptomatic, symptomatic to the life threatening shock syndrome. Traditionally, the DENV infection classified as Dengue Fever (DF), Dengue Hemorrhagic Fever and Dengue Shock Syndrome (DSS) [10]. A key features to differentiate DF and DHF is a plasma leakage, in which severe plasma leakage lead to hypovolemic shock (DSS) [11].

The pathogenesis of severe dengue is not fully elucidated, although studies of this have been conducted extensively. Nowadays, dengue immunopathogenesis included antibody enhancement theory (ADE), massive activation of $\mathrm{T}$-cell memories, and original antigenic sin [12].

Excessive productions of cytokines in DENV are proposed to induce endothelial instability and leakage. These condition termed cytokine storm has been associated with DENV severity elsewhere and proinflammatory cytokine such as Tumour Necrosis Factor$\alpha$ (TNF- $\alpha$ ), Interleukin (IL-1 $\alpha)$, IL-6, IL-8, IL-12, macrophage inhibitory protein-1-alpha (MIP-1 $\alpha$ ), MIP$1 \beta$, RANTES, Interferon gamma-induced protein 10 (IP10), Interferon gamma (IFN- $\gamma$ ) [13], TGF- $\beta$ [14], sVCAM [15], sICAM and many other soluble proteins has been found to be increase in DHF patient.

TNF- $\alpha$ is one of the inflammatory cytokine produced by mononuclear cells in response to an infection. This cytokine has been known a pivotal role in generating cytokines cascade orchestra in many inflammatory diseases. TNF- $\alpha$ also increases mediators through activation of lipid signal transduction such as prostaglandins and platelet activating factor [16].

Bali has become the most popular tourism destination in the world. Dengue infection has been found hyperendemic in Bali since all four DENV serotype circulate in Bali [17]. Travellers visiting Bali are at risk to get DENV infection during visiting Bali. Hence, a prospective study has been conducted in order to evaluate the profile one of the pro-inflammatory cytokine, TNF- $\alpha$, among travellers infected with DENV at Kasih Ibu Hospital Bali.

\footnotetext{
* Corresponding author: wayanwidhidewi@gmail.com
} 


\section{Material and methods}

\subsection{Patient Selection}

This study was a cross-sectional study on 41 serum of travellers infected with dengue virus that were admitted to the Kasih Ibu Hospital, Bali. The diagnosis was made on anamnesis, clinical findings, complete blood count and NS1 test. This study was approved by ethical committee of Universitas Udayana, Denpasar (Document number: 282/UN.14.2/KEP?2017).

\subsection{Laboratory Assay}

We obtain acute sera up to day 5 of onset of fever for detection of NS1 dengue antigen and DENV serotype detection as the definition dengue criteria. Detection of NS1 antigen was performed using the SD Bioline NS1 Rapid Test (Alere, Australia). Diagnosis of dengue was based on NS1 positive or detection of RNA dengue by reverse transcriptase PCR and Simplexa Real Time PCR.

Diagnosis of dengue hemorrhagic fever (DHF) was based on hematocrit difference more than $20 \%$ from acute to convalescence sera or the finding of pleural effusion or ascites on physical examinations. Grading of DHF was based on WHO criteria [18]. Status of DENV infection wether primary or secondary infection was based on the positivity of $\operatorname{IgG}$ anti dengue before the day $7^{\text {th }}$ of illness. Serum level of TNF- $\alpha$ were quantified using the Biolegend commercial ELISA assay kits, according to manufacturer's protocols. The patient's sera stored at $-80^{\circ} \mathrm{C}$ at Universitas Warmadewa until testing.

\subsection{Statistical Methods}

We analysed the TNF- $\alpha$ level among DF and DHF patients using SPSS 21.0 version.

\section{Result}

From the 41 of the total subjects in this study, almost a half of them included in the 31 - 45 age groups and majority of the sample were female (Table 1). The median age of the samples was 29 years old (range 15.473.1).

Table 1. Characteristic of Samples.

\begin{tabular}{|l|l|c|}
\hline \multicolumn{2}{|c|}{ Characteristic } & n (\%) \\
\hline Age Group (year) & & $1(2.4)$ \\
\hline & $0-15$ & $19(46.3)$ \\
\hline & $16-30$ & $13(31.7)$ \\
\hline & $31-45$ & $6(14.6)$ \\
\hline & $46-60$ & $2(4.9)$ \\
\hline Sex & $61-75$ & \\
\hline & & $16(39.0)$ \\
\hline & Male & $25(61.0)$ \\
\hline
\end{tabular}

Of 41 samples, NS1 antigen was positive in 40 $(97.56 \%)$ and PCR was able to detect the DENV in 32 $(78.05 \%)$ of the samples. Table 2 presented the laboratory finding of the samples. The lowest leucocyte and platelet number was found as low as $1 \times 109 \mathrm{cell} / \mu \mathrm{L}$ and $29 \times 109 \mathrm{cell} / \mu \mathrm{L}$, respectively.

Table 2. Laboratory finding.

\begin{tabular}{|l|c|c|}
\hline \multicolumn{1}{|c|}{ Variable } & \multicolumn{1}{|c|}{} \\
\hline $\begin{array}{l}\text { Nadir Leucocyte } \\
\text { (median/range) }\end{array}$ & & $2.1(1-4)$ \\
\hline $\begin{array}{l}\text { (Nadir Platelet } \\
\text { (median/range) }\end{array}$ & & $74(29-194)$ \\
\hline AST (median/range) & & $44(14-500)$ \\
\hline ALT(median/range) & & $35(7-430)$ \\
\hline Serotype,N(\%) & & $6(14.6)$ \\
DENV-1 & & $10(24.4)$ \\
DENV-2 & $12(29.3)$ \\
DENV-3 & & $3(7.3)$ \\
DENV-4 & & $1(2.4)$ \\
Mixed & & \\
\hline
\end{tabular}

There was almost equal finding of the DENV-2 and DENV-3 on the study. One case found to be infected with DENV-2 plus DENV-4 (concurrent dengue infection) with relatively mild dengue manifestation or having DF as the diagnosis. Table 3 showed that ninety percent of the subjects diagnosed with DF and the mean of TNF- $\alpha$ concentration in DHF patients were three times higher than DF patients.

Table 3. Level of TNF- $\alpha$ in DF and DHF Patients.

\begin{tabular}{|c|c|c|}
\hline \multirow{2}{*}{ Diagnosis } & $\mathbf{n}(\mathbf{\%})$ & TNF- $\alpha(\mathbf{X} \pm$ S.D) \\
\cline { 2 - 3 } & & \\
\hline DF & $37(90.2)$ & $8.32 \pm 12.36$ \\
\hline DHF & $4(9.8)$ & $28.39 \pm 30.17$ \\
\hline
\end{tabular}

The big four nationality of the samples was Germany, Russian, Dutch and Swedish, counted for $9(22 \%), 6(14.6 \%), 5(12.2 \%)$ and 4(9.8\%), respectively. The study define DENV infection as a secondary infection based on the positivity of IgG anti Dengue on the convalescence sera (on day 7 of DENV). The study found primary DENV infection was almost equal with secondary DENV infection (51.2 versus $48.8 \%)$. Bleeding was found as high as $5 / 41(12.20 \%)$ with vaginal bleeding as the most bleeding.

\section{Discussion}

Dengue is hyper-endemic in Indonesia and all 33 provinces of Indonesia have reported the incidence of dengue [19]. The intensive labor flow and travelers factors in Bali have been reported to contribute to the spread of DENV infection [20]. Previous reports indicated the hyperendemic transmission of all four DENV serotypes in Bali where circulating DENVs 
included dominant local strains, suggesting that Bali is a melting pot of substantial DENV diversity and serve as a hub for dengue transmission and mixing [17], [21].

The most predominant serotype detected was DENV3. This finding is similar with the result from local Balinese in 2015 where DENV-3 was predominant [17]. Our result was in contrast with data reported by Ernst, et al [21]. Which showed the predominance DENV found was DENV-2 in Australian travellers visiting Bali in 2010. The predominance of DENV-2 was also reported in other city in Indonesia in 2012 [22].

In term of DENV diagnosis, the study found DF as the majority diagnosis. Dengue fever is the mild form of DENV infection in which DF mostly found in the primary DENV infection. Since the travellers are from non-endemic country, it is reliable if the most clinical manifestation is mild dengue or manifest as DF. The local study also found that DF is the predominance clinical diagnosis among the local patients [22]. In term of the infection status, the majority of DENV infection was of primary infection. All the samples were collected from adult patients and since the travellers came from countries where dengue is not generally present (Figure 1), we may presume that they have contracted dengue for the first time during their visit to Bali.

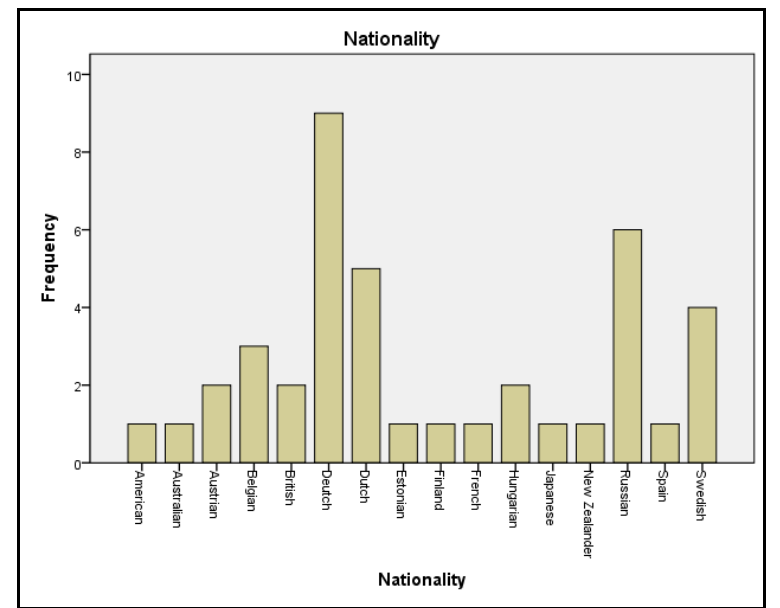

Fig. 1. Nationality of the samples.

The level of TNF- $\alpha$ in DHF sample is 3 times higher than DF samples. Since the number of DHF is not met the statistical analysis stipulation, this difference maybe is not suitable for generalization. Previous study reveals an increasing of TNF- $\alpha$ level during acute phase of DENV infection. [23] In contrast with other study that found no difference of TNF- $\alpha$ level between DHF and DF patients or also DSS.

The study limitation is the low sample size, study design and statistical analysis. Since the study is still ongoing, further samples recruitment will allow the best study result.

\section{Conclusion}

There is a difference of the TNF- $\alpha$ level in DF and DHF samples. The difference of TNF- $\alpha$ between DF and DHF need further statistical analysis to generalized to the population.

We thank R. Tedjo Sasmono, Ph.D and Benediktus Yohan, M Biomed, at Eijkman Institute for Molecular Biology for their great support to this study. We also would like to express our gratitude to the patients, nurses at Kasih Ibu Hospital Bali. This study was supported by Universitas Warmadewa Bali Indonesia.

\section{References}

1. WHO. Spec Program Res Train Trop Dis 409, 3 p147. (2009)

2. Bhatt S, Gething $\mathrm{P}$ W and Brady $\mathrm{O} J$ et al. Nature 4967446 p504. (2013)

3. Simmons C P, Farrar J J, Nguyen V V C and Wills B. N Engl J Me 366, 15 p1423. (2012)

4. Lambrechts L, Scott T W and Gubler D J. PLoS Negl Trop Di 4, 5 pe646. (2010)

5. Yacoub S, Mongkolsapaya J and Screaton G. Curr Opin Infect Dis 26, 3 p284. (2016)

6. Halstead S B. Dengue. (2008)

7. Muller D A, Young P R. Antiviral Res 98, 2 p192. (2013)

8. Chaudhry S, Swaminathan S and Khanna N. Dengue Bull 30, p121. (2016)

9. Jain B, Chaturvedi U C and Jain A. Microb Pathog 14, 1 p69-70. (2014)

10. Farrar J. In: Dengue p171. (2008)

11. Martina B E E, Koraka P and Osterhaus A D M E Clin Microbiol Rev 22, 4 p564

12. Rothman A L. Nat Rev Immunol 11, 8 p532. (2011)

13. Rathakrishnan A, Wang $\mathrm{S} M$ and $\mathrm{Hu} \mathrm{Y}$ et al. PLoS One 7, 12. (2012)

14. Basu A, Chaturvedi U C. FEMS Immunol Med Microbiol 53, 3 p287. (2008)

15. Koraka P, Murgue B and Deparis X et al J Med Virol 72, 3 p445

16. Parameswaran N, Patial S. Crit Rev Eukaryot Gene Expr 20, 2 p87. (2010)

17. Megawati D, Masyeni S and Yohan B et al. PLoS Negl Trop Dis 7, 5. (2017)

18. Who. WHO Fact Sheet 1. (2012)

19. Setiati T E, Wagenaar J F P, Kruif M D De and Mairuhu A T A. Dengue Bull 30, 1. (2006)

20. Yoshikawa M J, Kusriastuti R. Trop Med Health 41, 2 p67. (2013)

21. Ernst T, McCarthy S and Chidlow G et al. PLoS Negl Trop Dis 9, 1. (2015)

22. Nusa R, Prasetyowati $\mathrm{H}$ and Meutiawati $\mathrm{F}$ et al. J Infect Dev Ctries 8, 6 p733. (2014)

23. Ferreira R A X, de Oliveira S A and Gandini M et al. Acta Trop 149, 138. (2015) 